\title{
INVESTIGATION OF COEVAPORATED Cu(In,Ga)Se 2 THIN FILMS IN HIGHLY EFFICIENT SOLAR CELL DEVICES
}

\author{
C.A. Kaufmann ${ }^{1}$, T. Unold ${ }^{1}$, D. Abou-Ras ${ }^{1}$, J. Bundesmann ${ }^{1}$, A. Neisser ${ }^{1}$, R. Klenk ${ }^{1}$, \\ R. Scheer ${ }^{1}$, K. Sakurai ${ }^{2}$ and H.-W. Schock ${ }^{1}$ \\ ${ }^{1}$ Hahn-Meitner-Institut Berlin GmbH, Glienickerstrasse 100, 14109 Berlin, Germany \\ ${ }^{2}$ Unit 24412, AIST Central \#2, 1-1-1 Umezono, Tsukuba, Ibaraki 305-8568, Japan
}

In order to further improve $\mathrm{Cu}(\mathrm{In}, \mathrm{Ga}) \mathrm{Se}_{2}$ based thin film solar cell devices, it is important to understand the electronic defects in the absorber layer material. For this study $\mathrm{Cu}(\mathrm{In}, \mathrm{Ga}) \mathrm{Se}_{2}$ thin film solar cells with a layer sequence $\mathrm{Mo} / \mathrm{Cu}(\mathrm{In}, \mathrm{Ga}) \mathrm{Se}_{2} / \mathrm{CdS} / \mathrm{ZnO} / \mathrm{ZnO}: \mathrm{Al}$ have been produced on float glass substrates using a 3-stage coevaporation process together with a precise in-situ laser light scattering process control. The $\mathrm{Cu} /(\mathrm{In}+\mathrm{Ga})$ ratio has been varied by means of altering the duration of the 3rd stage of the process. Although the spectral quantum efficiencies measured on the resulting solar cell devices have not been affected by this variation, the open circuit voltage $V_{o c}$ measured under AM1.5 illumination increases when the final $\mathrm{Cu} /(\mathrm{In}+\mathrm{Ga})$ ratio of the absorber layer is closer to stoichiometry. Indium and gallium depth profiles, which are recorded as energy dispersive X-ray spectroscopy line scans along device cross sections, together with results from previously performed defect spectroscopy on identical samples, are correlated with the increase in $V_{o c}$. 


\section{Introduction}

Among thin film technologies, those based on the chalcopyrite $\mathrm{Cu}(\mathrm{In}, \mathrm{Ga}) \mathrm{Se}_{2}$ (CIGSe) have so far shown the highest efficiencies. For laboratory cells, a record efficiency of $19.5 \%$ has been reported [1]. Elaborate means for absorber layer fabrication such as the 3-stage physical vapour deposition (PVD) process have been designed in order to carefully control the properties of the deposited layers [2]. For better understanding of the CIGSe formation during the deposition process, its effects on the absorber layer properties and the final solar cell device performance, CIGSe thin films from various process variations have been carefully studied [2-4]. The presented work provides additional information on this topic.

Similar to experiments performed by Keyes et al. [3], CIGSe absorber layers with a varied $\mathrm{Cu}$-content were prepared. After the $\mathrm{Cu}$-content has exceeded stoichiometry in the 2nd phase of the 3-stage PVD process, and the layer compound is then taken back to a $\mathrm{Cu}$-poor composition by evaporation of In, Ga and Se only during the 3rd phase, complex changes have been observed in the layer morphology, the material's microstructure and the defect chemistry [2-4]. Thus a limited number of samples were processed with different durations for phase 3 and studied by scanning electron microscopy (SEM) and energy dispersive X-ray analysis (EDX) in order to investigate morphology and composition. For characterisation of the defect chemistry and electronic properties, identical samples from the same fabrication processes have recently been investigated using photoluminescence (PL) and capacitancevoltage profiling [5]. The results from both analyses are put into context and discussed in view of the resulting solar cell performance.

\section{Experimental}

CIGSe thin films have been grown on Mo coated float glass substrates using a 3-stage PVD process $[2,6]$. The In-Ga-Se precursors, which result form the 1st phase of the PVD process, are assumed homogeneous in composition if not Ga-rich at the back surface. The $\mathrm{Cu}$-content 
of the completed CIGSe layers is determined purely by the duration of the 3rd phase $t_{3}$ of the process. The nominal $\mathrm{Cu} /(\mathrm{In}+\mathrm{Ga})(\mathrm{Cu} / \mathrm{III})$ ratios used for the present study are $0.96,0.92$ and 0.88 , determined by the ratios of the duration of the phases 3 and $1\left(\mathrm{t}_{3} / \mathrm{t}_{1}\right): 0.20,0.25$ and 0.30 . The In, Ga and Se flux in phases 1 and 3 is assumed nominally equal. After having reached the point of stoichiometry in deposition phase $2, \mathrm{Cu}$ and Se evaporation was continued for a duration $\mathrm{t}_{2 \mathrm{a}}$, with $\mathrm{t}_{2 \mathrm{a}} / \mathrm{t}_{2}=0.15$. Laser light scattering is used as in-situ process control [7]. From the CIGSe absorber films solar cells with a total area of $0.5 \mathrm{~cm}^{2}$ were prepared by consecutive deposition of a CdS buffer layer by chemical bath, an RF-sputtered transparent $\mathrm{ZnO} / \mathrm{ZnO}$ :Al bi-layer front contact and, in order to facilitate current collection, an evaporated $\mathrm{Ni} / \mathrm{Al}$ contact grid. As the CIGSe layers are $\mathrm{Cu}$-deficient in composition no chemical treatment was performed prior to the $\mathrm{CdS}$ deposition.

Fig. 1 shows the netto counts of an EDX line scan that has been recorded across a cross section of a complete solar cell device. EDX line scans were acquired in an SEM using an acceleration voltage of $7 \mathrm{keV}$. This results in a penetration depth of approximately $0.3-0.4 \mu \mathrm{m}$ and consequently a spatial resolution of approx. $200 \mathrm{~nm}$ is assumed. It should be noted that this estimation assumes a homogeneous composition of the analysed volume which is only correct in the bulk area of the absorber. Lines between measurement points are used as guide to the eye.

Solar cell devices were characterised by recording $I$ - $V$-characteristics under standard AM1.5 illumination and external quantum efficiency measurements (EQE).

\section{Results}

\section{Morphology and Composition}

Fig. 2 shows cross sectional SEM images of the CIGSe solar cell devices with different $\mathrm{Cu} / \mathrm{III}-$ ratios. Large grains are visible for all three absorbers. 
On these cross sections EDX line scans have been acquired, and the netto counts for the In-L and Ga-L peaks, normalized to the Se-K peak, are shown in Fig. 3. Netto counts are directly correlated to the concentration of the corresponding element in the investigated region but do not reflect absolute compositional values. Hence, the line scans in Fig. 3 refer to relative compositional changes in the absorber. Two line scans, recorded on different grains, are shown for each sample in order to illustrate reproducibility across the device. For all three samples studied, Ga has the tendency to accumulate at the back of the CIGSe layer, near the Mo back contact. Simultaneously the In signal decreases for all three samples when moving the probe towards the back contact. What is different for the studied samples is the ratio of the In and Ga signals near the front of the device. For the CIGSe film with a composition nearest to stoichiometry, the Ga/In-ratio near the heterointerface seems to be highest (see Fig. 3a) and decreases when increasing the amount of In-Ga-Se provided in phase 3 (see Fig. 3b and 3c). Finally, Fig. 4 shows the netto count for the $\mathrm{Cu}-\mathrm{L}$ signal, also normalized to the Se-K peak. These $\mathrm{Cu}-\mathrm{L}$ netto counts correspond well to the nominal $\mathrm{Cu} / \mathrm{III}-$ ratios for the different layers. Within the accuracy of the measurements, the $\mathrm{Cu}$ distribution across the CIGSe layers does not show any significant gradients.

\section{Defects, Electronic Properties and Solar Cell Performance}

Identical devices from the same absorber deposition processes were investigated in order to characterize defects and carrier concentration in relation to the final $\mathrm{Cu} / \mathrm{III}-$ ratio of the absorber [5]. The authors reported highly non-uniform profiling densities with a minimum at about $400-500 \mathrm{~nm}$ from the heterointerface. The corresponding capacitance-voltage profiles are shown in Fig. 5. A higher $\mathrm{Cu} / \mathrm{III}-$ ratio results in a higher profiling density (carrier density + defects). For the device with $\mathrm{Cu} / \mathrm{III}=0.96, \mathrm{PL}$ measurements at room temperature have identified an additional defect band with an ionization energy of $130 \mathrm{meV}$, which is tentatively attributed to an acceptor level caused by indium vacancies. 
The solar cell performances of the devices corresponding to the different final $\mathrm{Cu} / \mathrm{III}-$ ratios are given in Table 1. A 'best' value is shown for the best cell of each experiment. The 'average' shows a mean value for up to 21 cells from the same substrate. $\mathrm{For} \mathrm{Cu} / \mathrm{III}=0.88$, some cells were shunted due to macroscopic device defects and were hence not included in the average. Variations in the total area $j_{s c}$ are attributed to a slight error in the patterning process. However, general trends in $V_{o c}$ and $F F$ seen in the 'best' devices are confirmed by the 'average' results. The $V_{o c}$ can be seen to increase along with increasing $\mathrm{Cu} / \mathrm{III}$. Simultaneously, the fill factor $F F$ decreases. In Fig. 6 on the other hand, the EQEs for the devices from the absorber layers with varied $\mathrm{Cu} / \mathrm{III}-$ ratio, indicate the same photoactive energy band gap at $1.19 \mathrm{eV}$.

\section{Discussion}

In agreement to what was reported above, for In-Ga-Se precursors that are homogeneous in composition and for those which are Ga rich near the back surface, $\mathrm{Ga}$ accumulation near the back contact within the final CIGSe film has also been observed by other authors [2]. The fact that the gallium signal is reduced in relation to the indium signal near the heterointerface as the duration of the 3rd deposition phase increases (compare Fig. 3a to 3c), implies an effective transport mechanism of Ga towards the back of the sample. This proportional decrease in the Ga signal, and hence a reduced energy band gap of the material at the heterointerface, qualitatively agrees with the change seen in the open circuit voltage $V_{o c}$ of the devices. From the EQE (Fig. 6) it is however clear that the minimum band gap in the photoactive region of the resulting CIGSe devices is not affected. Considering that the In/Ga-ratio of the evaporation flux is kept constant during phase 3 and that the variation in the deposition processes is only in the duration of this final process phase, the latter seems to be the main determining factor for the development of the In-Ga-profiles. This means, that, once the sample is nominally $\mathrm{Cu}$-poor in phase 3 , Ga diffusion towards the back contact does not 
necessarily cease and that a further study of the compositional gradients within the surface near region of the CIGSe layers with a method that provides higher spatial resolution is of immense interest.

The increase in the profiling density that is seen for the $\mathrm{Cu}$-rich samples (Fig. 5) also correlates with the increase in $V_{o c}$ (Table 1). As for the sample with $\mathrm{Cu} / \mathrm{III}=0.96$, this may be related to the presence of indium vacancies and since in Fig. 3 the In/Ga-ratio is lowest in the absorber region near the heterointerface, a spatial localisation for the indium vacancies in this area is suggested.

We attribute the decrease in the $F F$ for high $\mathrm{Cu} / \mathrm{III}-$ ratios to additional shunt paths that may be caused by the presence of remaining areas of $\mathrm{Cu}_{x} \mathrm{Se}$, e.g. along grain boundaries [5].

\section{Conclusion}

The investigation of CIGSe based thin film solar cell devices, prepared from absorber layers with different $\mathrm{Cu} / \mathrm{III}$-ratios after phase 3 of the 3 -stage coevaporation process, shows a correlation of the duration of phase 3 , i.e. the final $\mathrm{Cu}$-content of the absorber, with the In and Ga profiles as they are measured by EDX line scans on device cross-sections. An increased $V_{o c}$ is obtained for the devices with the absorber composition closest to stoichiometry. This coincides with a lower In/Ga-ratio near the heterojunction when compared to samples from processes with a more extended phase 3 , plus an increased profiling density within the absorber. The latter is associated with an additional defect level, possibly indium vacancies.

\section{Acknowledgements}

The authors would like to thank N. Blau, B. Bunn, T. Enzenhofer, C. Kelch, M. Kirsch, P. Körber, T. Münchenberg, D. Schweigert and M. Wilhelm for technical support and scientific discussions. 


\section{References}

1. M.C. Contreras, K. Ramanathan, J. AbuShama, F. Hasoon, D.L. Young, B. Egaas and R. Noufi, Progress in Photovoltaics: Research and Applications 13 (7) (2005) 209

2. A.M. Gabor, J.R. Tuttle, M.H. Bode, A.Franz, A.L. Tennant, M.A. Contrereas, R. Noufi, D. Garth Jensen, A.M. Hermann, Solar Energy Mat. And Sol. Cells 41/42 (1996) 247

3. B.M. Keyes, P. Dippo, W. Metzger, J. Abushama and R. Noufi, Proceedings of the $29^{\text {th }}$ IEEE Photovoltaics Specialist Conference, New Orleans, 2002

4. R. Noufi, Y. Yan, J. AbuShama, K. Jones, M. Al-Jassim, B. Keyes, J. Alleman, K. Ramanathan, Proceedings of the $29^{\text {th }}$ IEEE Photovoltaics Specialist Conference, New Orleans, 2002

5. T. Unold, T. Enzenhofer, C.A. Kaufmann, R. Klenk, A. Neisser, K. Sakurai, H.-W. Schock, Proceedings of the 4th World Conference on Photovoltaic Energy Conversion, Hawaii, 2006 - in the press

6. C.A. Kaufmann, A. Neisser, R. Klenk, R. Scheer, Thin Solid Films 480/481 (2005) 515

7. R. Scheer, A. Neisser, K. Sakurai, P. Fons and S. Niki, Applied Physics Letters 82 (13) (2003) 2091 


\section{Tables}

Table 1: Characteristic values for the I-V measurement of cells made from absorbers with different $\mathrm{Cu} /\left(\mathrm{In}+\mathrm{Ga}\right.$ ) ratios; $\mathrm{j}_{\mathrm{sc}}$ (active) refers to the current density that is determined via the external quantum efficiency, whereas $\mathrm{j}_{\mathrm{sc}}$ (total) is determined by the measured $\mathrm{I}-\mathrm{V}$ characteristic considering the total device area.

\begin{tabular}{c||cccc||ccccc}
\hline \multicolumn{1}{l||}{} & \multicolumn{4}{c||}{ Best } & \multicolumn{5}{c}{ Average } \\
\hline \multirow{2}{*}{$\mathrm{Cu} / \mathrm{III}$} & $\begin{array}{c}\mathrm{V}_{\mathrm{oc}} \\
{[\mathrm{mV}]}\end{array}$ & $\begin{array}{c}\mathrm{FF} \\
{[\%]}\end{array}$ & $\begin{array}{c}\mathrm{j}_{\mathrm{sc}}(\text { active }) \\
{\left[\mathrm{mA} / \mathrm{cm}^{2}\right]}\end{array}$ & $\begin{array}{c}\eta \\
{[\%]}\end{array}$ & $\begin{array}{c}\text { Number } \\
\text { of cells }\end{array}$ & $\begin{array}{c}\mathrm{V}_{\mathrm{oc}} \\
{[\mathrm{mV}]}\end{array}$ & $\begin{array}{c}\mathrm{FF} \\
{[\%]}\end{array}$ & $\mathrm{j}_{\mathrm{sc}}$ (total) & $\eta$ \\
\hline 0.96 & 701 & 74.3 & 32.1 & 16.8 & 21 & 700 & 73.8 & 31.6 & 16.3 \\
0.92 & 684 & 75.8 & 32.0 & 16.7 & 21 & 683 & 75.7 & 32.4 & 16.7 \\
0.88 & 667 & 76.5 & 32.1 & 16.6 & 16 & 665 & 76.1 & 31.8 & 16.1 \\
\hline
\end{tabular}




\section{Figure Captions}

Figure 1: Netto counts of an energy dispersive X-ray analysis linescan across a CIGSe thin film solar cell device.

Figure 2: Cross sectional scanning electron microscopy images of solar cells from $\mathrm{Cu}(\mathrm{In}, \mathrm{Ga}) \mathrm{Se}_{2}$ layers with different $\mathrm{Cu} /(\mathrm{In}+\mathrm{Ga})$ ratios $(\mathrm{Cu} / \mathrm{III})$.

Figure 3: Energy dispersive $\mathrm{X}$-ray analysis linescans across the $\mathrm{Cu}(\mathrm{In}, \mathrm{Ga}) \mathrm{Se}_{2}$ devices with varied phase 3 duration; displayed are the netto counts recorded for the In-L and Ga-L peaks after normalization to the Se-K peak.

Figure 4: Energy dispersive X-ray analysis linescans across the $\mathrm{Cu}(\mathrm{In}, \mathrm{Ga}) \mathrm{Se}_{2}$ devices with varied phase 3 duration; displayed are the netto counts recorded for $\mathrm{Cu}$ after normalization to the Se peak.

Figure 5: Capacitance-voltage profiles acquired at room temperature using a measurement frequency of $100 \mathrm{kHz}$ [5].

Figure 6: External quantum efficiency of the solar cell devices from $\mathrm{Cu}(\mathrm{In}, \mathrm{Ga}) \mathrm{Se}_{2}$ layers with different $\mathrm{Cu} /(\mathrm{In}+\mathrm{Ga})$ ratios $(\mathrm{Cu} / \mathrm{III})$. 
Figure 1

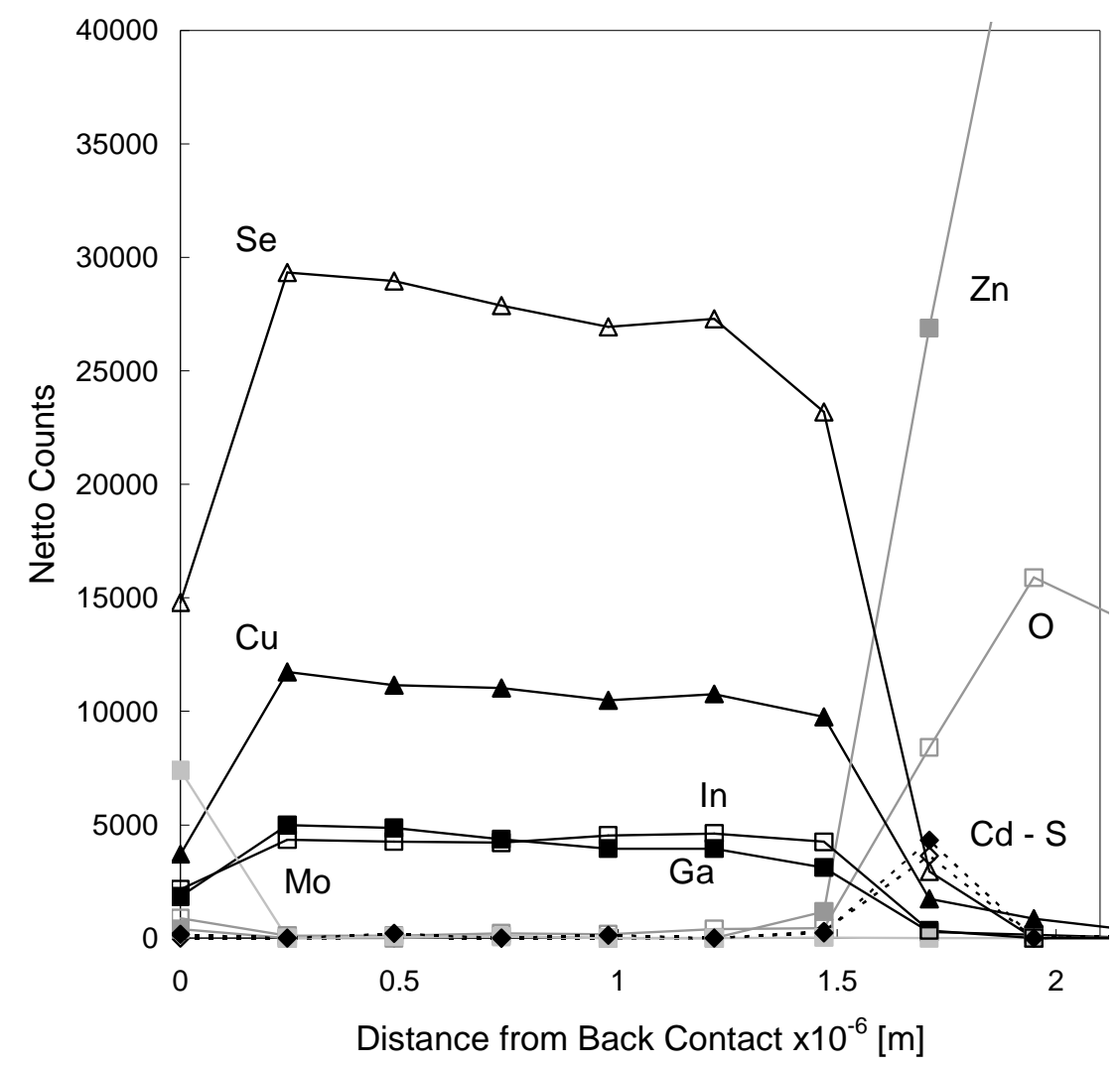


Figure 2

\section{$\mathrm{Cu} / \mathrm{II}=0.96 ; 3 / 1=0.20$}
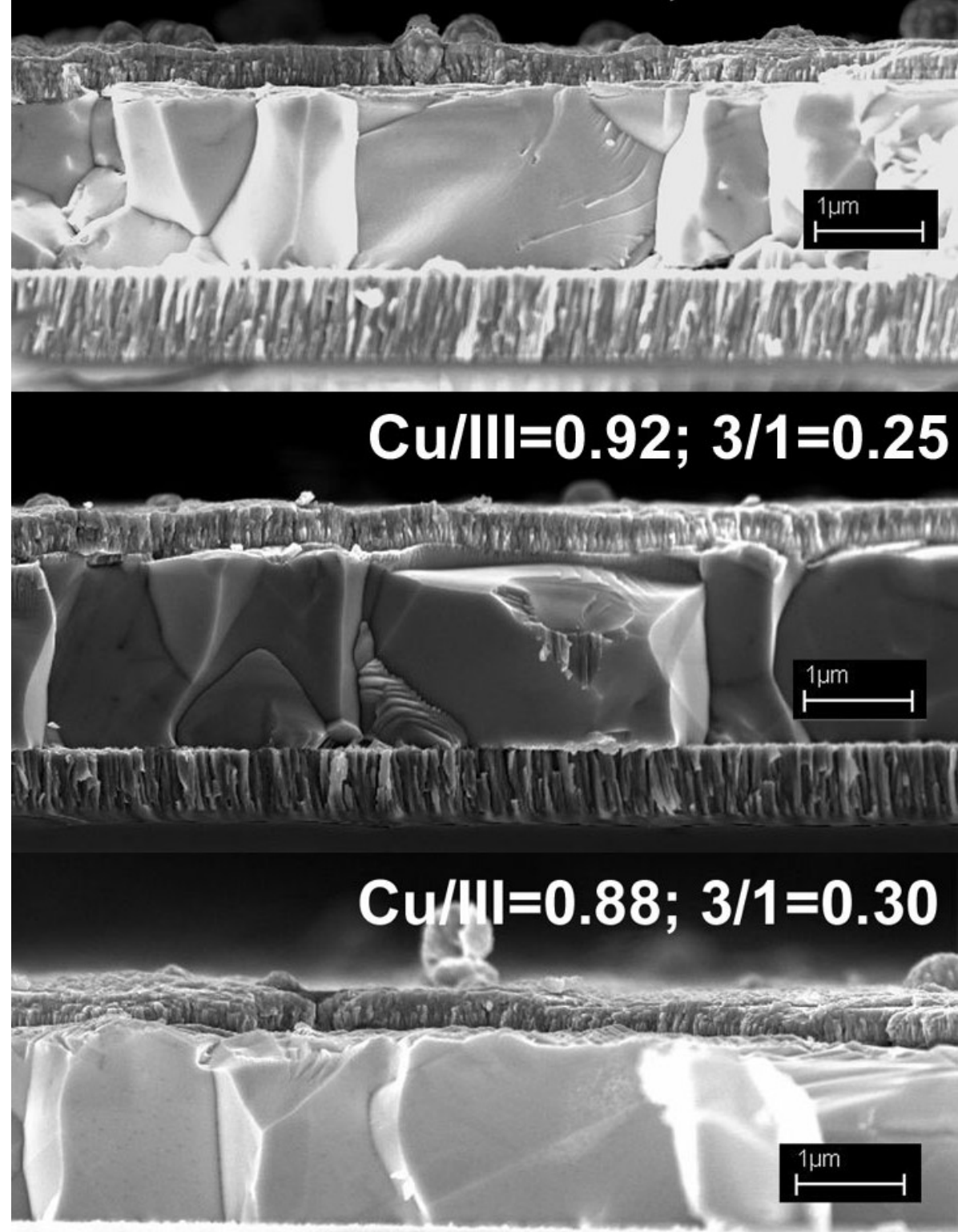
Figure 3
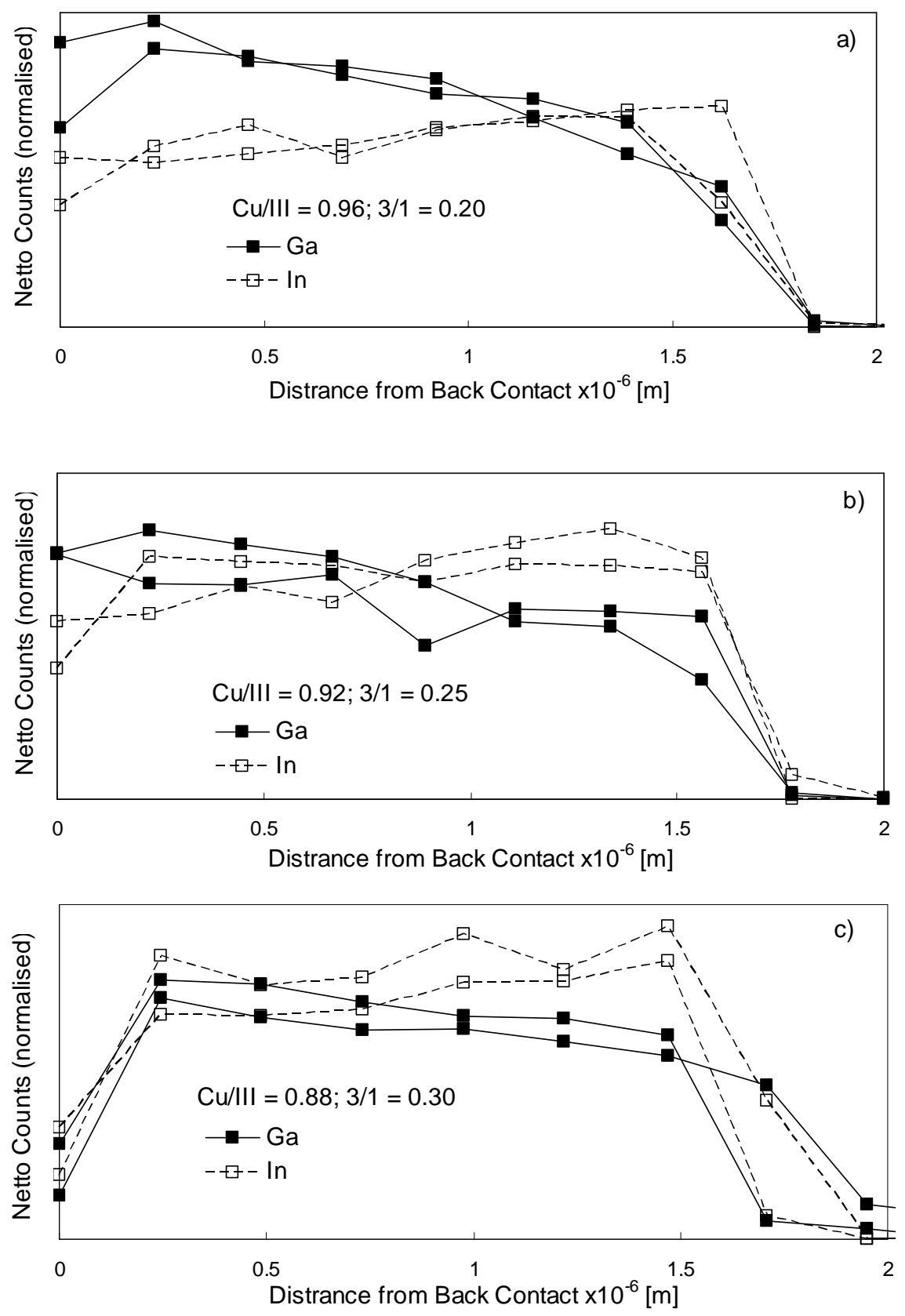
Figure 4

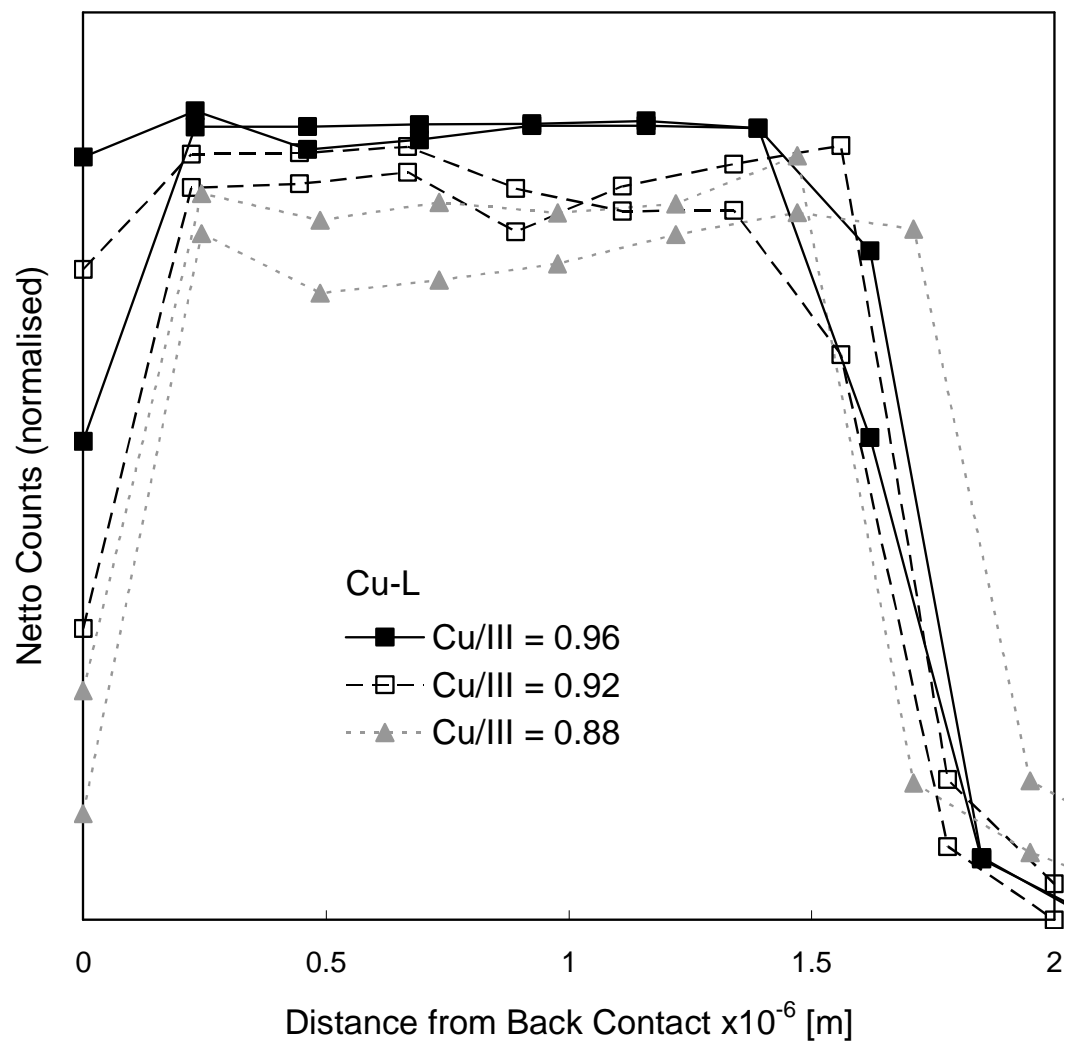


Figure 5

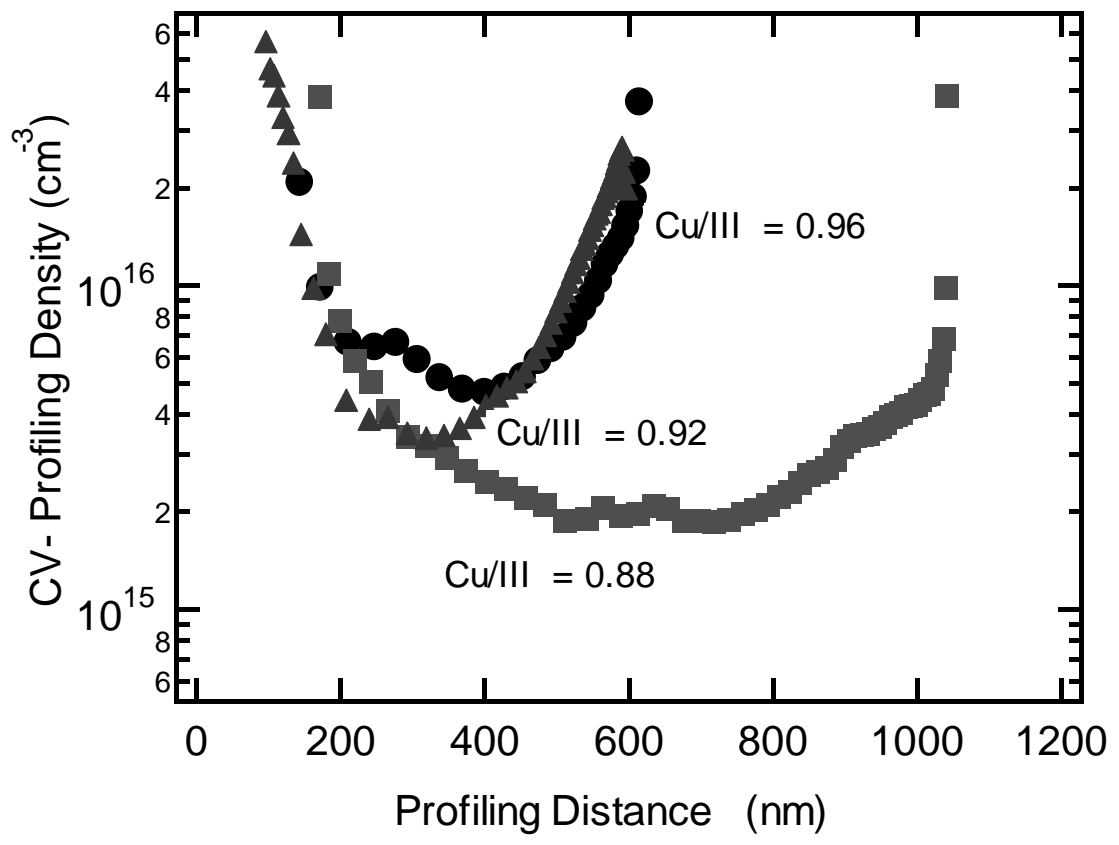


Figure 6

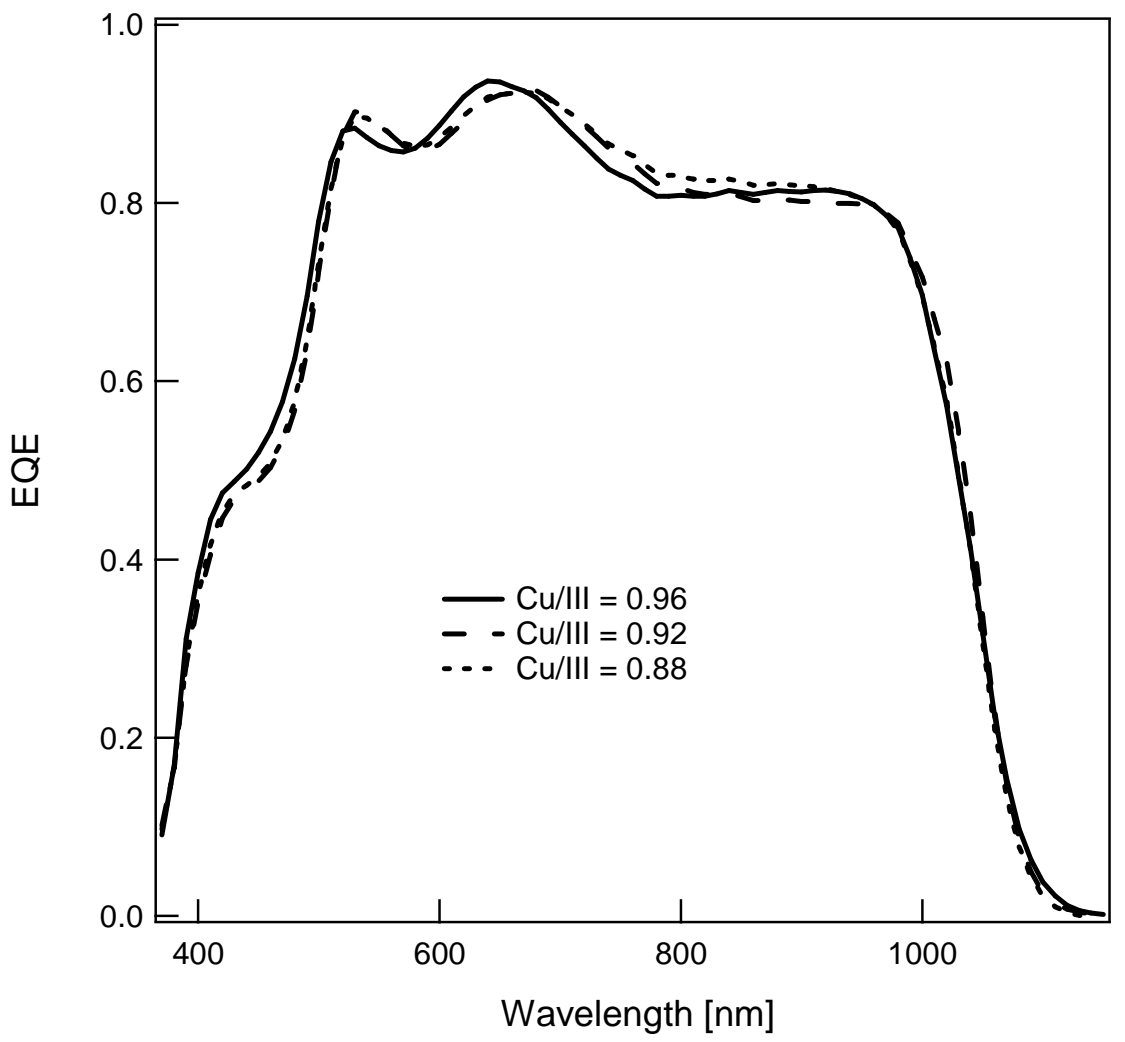

